Алексеенко А.А., Колесников А.Н.

Государственная образовательная организация высшего профессионального образования «Донецкий национальный медицинский университет имени М. Горького»

\title{
ИСПОЛЬЗОВАНИЕ РЕЖИМА ВСПОМОГАТЕЛЬНОЙ ВЕНТИЛЯЦИИ ЛЕГКИХ РSV ДЛЯ ПРОВЕДЕНИЯ АНЕСТЕЗИИ В АМБУЛАТОРНЫХ УСЛОВИЯХ
}

\section{АКТУАЛЬНОСТЬ}

Довольно серьёзным вопросом для анестезиолога, в условиях стационара одного дня, является протекция функции дыхания для пациента при проведении общей анестезии, особенно продолжительной. Учитывая все особенности, связанные с работой в амбулаторных условиях, анестезиологу приходится задумываться о применении такого ряда препаратов, как миорелаксанты, в связи с их возможными отдалёнными осложнениями [Авдеева, Т. Г.]. Наиболее важным моментом в осмыслении принципов респираторной поддержки представляется проблема - «больной не синхронен с аппаратом!». Необходимо осознать, что сопротивление пациента работе вентилятора (десинхронизация системы «пациент -респиратор») свидетельствует - несоответствии параметров работы респиратора потребностям пациента. Следовательно, именно вентилятор необходимо адаптировать к потребностям пациента, а не пациента к механическому аппарату. Таким образом, тактика врача всегда состоит в том, чтобы детально понять потребности больного и в соответствии с ними оптимизировать работу респиратора [В.Д. Малышев]. Строго говоря, единственным полностью принудительным, не адаптирующимся к запросам больного, режимом является CMV с выключенным триггером (триггер по времени). Данный режим - применим только у полностью релаксированного пациента [Bayram. B].

Современные аппараты искусственной вентиляции легких отличаются ориентацией на вспомогательные режимы вентиляции, наличием микропроцессорного управления всеми параметрами вентилятора, расширенными возможностями мониторирования параметром респираторной механики пациента, а также-

Алексеенко А.А. и соавт. развитой системой тревог для отслеживания опасных отклонений [Dreyfuss. D]. Новые режимы вентиляции могут быть трудны для понимания и клинического применения, хотя они предоставляют больше вариантов лечения, чем традиционные режимы [Ramirez. G]. По данным авторов В. В Мороза, В. В. Лихванцева режим вспомогательной вентиляции Pressure Support Ventilation очень хорошо зарекомендовал себя при следующих видах оперативных вмешательств:

дискэктомиях при грыжах межпозвонковых дисков на поясничном уровне, удалениях опухолей корешков, тиреоид-

эктомиях, мастэктомиях с одномоментной TRAM пластикой, резекциях желудка, лапароскопических герниопластиках.

Альтернативные способы вентиляции являются инструментами для защиты и освобождения от принудительной вентиляции легких. Понимание функции и применения этих альтернативных режимов перед внедрением очень важно и наиболее полезно для пациента [Gallagher. J.].

\section{ЦЕЛЬ РАБОТЫ}

Внедрить режим вспомогательной вентиляции легких PSV для проведения анестезии в амбулаторных условиях.

\section{МАТЕРИАЛ И МЕТОДЫ}

Внедрение методики проводилось в «студии имплантологии доктора Дзюбы» г. Донецк и стоматологии «Экселенс» г. Ростов-на-Дону.

Анестезиологическое обеспечение 126 пациентов (54 мужчин и 72 женщины) проводилось при различных видах оперативного стоматологического лечения методом проведения общей ингаляционной анестезии севофлюраном. Протекция функции дыхания осуществлялась вспомогательной искусственной вентиляцией легких в режиме вентиляции Pressure support ventilation с ограничением как по объёму так и по давлению и протекцией дыхательных путей с помощью назотра- 
хеальной интубации.

РЕЗУЛЬТАТЫ ИССЛЕДОВАНИЯ

В премедикацию назначали внутривенное введение атропина 0,1\% - 0,01-0,02 мг/кг, дексаметазона в дозе 0,2 мг/кг, лидокаина 1,5 мг / кг (максимально - 100 мг). После индукции в анестезию пропофолом в дозе 2 - 2,5 мг/кг проводилась крикотиреоидная анестезия и назотрахеальная интубация трахеи.

Поддержание общей ингаляционной анестезии севофлюраном (поток кислорода до 1 л в минуту) и содержанием севофлюрана 2-3 об\%. Обезболивание местной инфильтрационной и проводниковой анестезией раствором убистезина $4 \%$ с эпинефрином 1:100 000 в полном объем в комбинации с безопиоидной анестезией на основе внутривенной инфузии лидокаина.

Преимуществарежимавентиляциилегких PSV по сравнению с принудительными режимами вентиляции:

1) возможность отказа от релаксантов;

2) уменьшает внутрилегочное шунтирование крови;

3) предотвращает снижение сердечного индекса;

4) профилактика усталости диафрагмы;

5) переключение с вдоха на выдох происходит в соответствии с логическими физиологическими принципами;

6) возможность экстубации во сне;

7) предсказуемость пробуждения;

8) значительно ускоряет процесс

пробуждения после анестезии.

Проведение ИВЛ в режиме «PSV» требует наличия самостоятельных дыхательных попыток. Для профилактики возможной гипоксии и гиперкапнии в результате медикаментозной

дыхания, обязательна установка апнойной вентиляции и обязательный контроль Sp02, PetCO2. Параметры отдельного вдоха апнойной вентиляции устанавливались соответственно параметрам обязательного вдоха в алгоритме SIMV или CMV. ОБСУЖДЕНИЕ
По данным статистического анализа интраоперационных показателей мониторинга оперативное лечение с применением режима вспомогательной вентиляции PSV и ингаляционной анестезией севофлюраном отличается стабильностью и отсутствием самоиндуцированного повреждения легких, и отсутствует достоверное отличие на этапах исследования: Sp02, PetCO2, гемодинамические показатели, что говорит о безопасности внедренного метода. Обращает на себя внимание отсутствие необходимости увеличения МАК для достаточного уровня седации при проведении вентиляции легких. После прекращения подачи севофлюрана производилась экстубация трахеи в состоянии медикаментозного сна. Через 2-10 минут появлялись элементы сознания и двигательной активности.

\section{ЗАКЛЮЧЕНИЕ}

Режим вспомогательной вентиляции Pressure Support Ventilation нивелирует отрицательные эффекты принудительной вентиляции легких, позволяет сохранить физиологические аспекты дыхания и отказаться от интраоперационного применения миорелаксантов. В результате проведенного исследования доказана целесообразность использование режимa PSV для проведения анестезии в амбулаторных условиях.

\section{Сведения об авторах}

Алексеенко А.А., врач-анестезиолог высшей категории, ассистент кафедры анестезиологии, реаниматологии и неонатологии ГОО ВПО ДОННМУ ИМ.М. ГОРЬКОГО, тел. +380713579959, e-mail alexeyenko3@ukr.net

Колесников А.Н., д.мед.н., профессор, зав. кафедрой анестезиологии, реаниматологии и неонатологии ГОО ВПО ДОННМУ ИМ.М. ГОРЬКОГО, +380713134370,

e-mail akolesnikov1972@gmail.com 